\title{
Features of the use of PID controllers when controlling evaporators
}

\author{
Oleg Zubkov \\ ORCID 0000-0002-8528-6540 \\ Department of Microprocessor \\ Technologies and Systems \\ Kharkiv National University of Radio \\ Electronics \\ Kharkiv, Ukraine \\ oleh.zubkov@nure.ua
}

\author{
Iryna Svyd \\ ORCID 0000-0002-4635-6542 \\ Department of Microprocessor \\ Technologies and Systems \\ Kharkiv National University of Radio \\ Electronics \\ Kharkiv, Ukraine \\ iryna.svyd@nure.ua
}

\author{
Oleksandr Maltsev \\ ORCID 0000-0003-1520-9280 \\ Department of Microprocessor \\ Technologies and Systems \\ Kharkiv National University of Radio \\ Electronics \\ Kharkiv, Ukraine \\ aleksandr.maltsev@nure.ua
}

\begin{abstract}
In the work, the features of the use of PID regulators for controlling evaporators are theoretically and experimentally analyzed, an algorithm for controlling the heating element of the evaporator is developed, and practical recommendations are given for choosing the parameters of the PID controller.
\end{abstract}

Keywords-PID controller, evaporator, microcontroller, algorithm, vapor

\section{INTRODUCTION}

In many automated control systems for technological processes in production, boiler equipment, electric motor control systems, proportional-integral-differential controllers (PIDs) are used. With their help, a constant value of any technological parameter is maintained. For example, a constant value of the temperature of the heat carrier in heating or cooling systems. The regulation problem in modern control systems is solved by microcontrollers in combination with measuring sensors and power modules. The theoretical foundations of the operation of classical PID controllers and their settings have been studied and described in many literature sources [1-4]. However, there is a specific group of control devices for which it is necessary to modernize the algorithms of the PID regulators and their mathematical description. These are vaporizers. In such devices, the process of liquid boiling takes place, in which all the energy transferred from the heating element to the evaporator is used not to increase the temperature of the liquid, but to transfer the liquid to vapor [5]. In evaporators, the PID regulator must maintain a fixed value of the volume of steam generated per unit of time. At the same time, when the PID controller is turned on, its reaching the operating mode is complicated by the fact that the thermodynamic processes in the evaporator before boiling and during boiling are different. These scientific studies were devoted to solving these problems, which are relevant for automated control systems. The solution of these main problems is inextricably linked with a number of aspects of an applied nature: the type of measurements - direct or indirect, the location of the measuring sensors, the choice of the measurement period and the correction period for the control action. Therefore, the purpose of the research was to develop an evaporator control algorithm and form recommendations for the selection of PID controller parameters.

\section{THEORETICAL PART}

The principle of operation of the PID controller is that based on the measurement result of the main output parameter of the controlled system, the deviation of the current value from the required value is calculated and the value of the corrective action on the system is calculated $[1,3]$

$$
u(t)=P+I+D=K_{p} e(t)+K_{i} \int_{0}^{\tau} e(t) d t+K_{d} \frac{d e}{d t}
$$

where $P$ is proportional component; $I$ is integral component; $D$ is differential component; $e(t)$ is current error; $K p$ is proportional factor; $K i$ is integral coefficient; $K d$ is differential coefficient.

For evaporators with direct measurements, the main output parameter is the amount of steam generated. However, steam flow meters are very expensive devices with high measurement errors and specific measurements for various types of steam (water, alcohol, etc.). Therefore, when controlling the majority of modern evaporators, indirect measurements of vaporization are used through the temperature of the heating elements of the evaporator. Temperature is directly related to the amount of energy transferred to the evaporator and, accordingly, to the amount of steam generated.

Formula (1) is a continuous form of PID controller representation, which requires conversion to a discrete form for implementation on a microcontroller [2].

$$
\begin{aligned}
& u(k)=K_{p}\left\{\Delta x(k)+\frac{T_{0}}{T_{\text {int }}} \sum_{i=0}^{k} \Delta x(i-1)+\right. \\
& \left.+\frac{T_{d}}{T_{0}}[\Delta x(k)-\Delta x(k-1)]\right\},
\end{aligned}
$$

where $k$ is discrete moment in time $\left(k T_{0}\right) ; T_{\text {int }}$ is constant of integration; $T_{\mathrm{d}}$ is differentiation constant; $T_{0}$ is sampling period. 


\section{EQUIPMENT OF THE EXPERIMENTAL SYSTEM}

As heating elements of the evaporation system, $2 \mathrm{~kW}$ electric heaters with triac control were used. Therefore, the PID regulator provided control of the electrical power transmitted to the load. Thermal resistances of the Pt1000 type were used to measure the temperature. In the board of the controller for controlling the triac, a circuit for detecting the zeros of the mains voltage is implemented, which made it possible to implement two main methods of controlling the triac during research: passing a part of the half-cycle of the mains voltage into the load or passing one of the set of halfperiods. The controllers of the STM32F1 and STM32F4 series were chosen as control controllers.

\section{StUdy RESUlts AND PRACTICE RECOMMENDATIONS FOR EVAPORATOR CONTROL SYSTEMS}

The software implementation of the standard PID controller operation algorithm according to (2) showed that the process of turning on the system is significantly extended in time in comparison with the calculation results, and overshoot is also observed in the control system. This is due to the transition from heating to boiling. To eliminate these effects at the initial stage of inclusion in the algorithm, a forced mode is introduced. In this mode, the power of the heating elements is maintained at a maximum until a predetermined temperature threshold is reached, the value of which can be either less than the operating value or higher. After that, the PID controller is turned on. However, at this moment the value of the integral component is equal to 0 , since the integration is not performed from the moment the system is turned on. Therefore, the parameter of the initial value of the integral component is introduced, which makes it possible to compensate the accumulated value from the moment the system is turned on. The use of the forced mode ensured a quick activation of the system and the absence of fluctuations in the control system. Experimental studies have also shown that when the user gives commands to reduce the amount of steam per unit of time, the response value of the PID controller can drop to 0 . This can lead to the termination of boiling, which is unacceptable for the evaporator. Therefore, a limitation was introduced on the minimum value of the control action of the PID controller.

Taking into account the proposed improvements, expression (2) was transformed to the form

$$
u(k)=\left\{\begin{array}{l}
u_{\max }, \mathrm{i}<\mathrm{k}_{\text {START }} \\
u_{\min }, u(k)<u_{\min }, \mathrm{i}>=\mathrm{k}_{\text {START }} \\
K_{p}\left(\Delta x(k)+I_{\text {START }}+\frac{T_{0}}{T_{\mathrm{int}}} \sum_{i=k_{\text {START }}}^{k} \Delta x(i-1)+\right. \\
\left.+\frac{T_{d}}{T_{0}}[\Delta x(k)-\Delta x(k-1)]\right)
\end{array}\right.
$$

where $u_{\max }$ the maximum power value of the evaporator heating elements; $u_{\min }$ the minimum value of the power supplied to the heating element in the operating mode of the evaporator; $k_{\mathrm{START}}$ moment of time from switching on to switching off the forced mode; $I_{\text {START }}$ the initial value of the integral component at the moment of switching off the forced mode.

The optimal location for the temperature sensor is the outer surface of the heating element, since this provides a wide dynamic range of temperature measurements for the heating element. In the research stand, it reached $60^{\circ} \mathrm{C}$.

Since the developed control algorithm was implemented on modern 32-bit microcontrollers with an ARM core, all calculations in the PID controller were performed with floating point. For STM32F1 microcontrollers, the calculation time does not exceed $80 \mu \mathrm{s}$, and for STM32F4 microcontrollers, no more than $1 \mu$ s due to the hardware DSP block. Thus, even the cheap STM32 microcontroller series can implement one or more PID controllers.

\section{CONCLUSION}

According to the classical theory of PID controllers, the differential component is influenced by noise, which manifests itself as fluctuations in the temperature measurements of the heating elements over time. With a normal distribution of measurement errors, the standard deviation decreases in proportion to the square root of the number of measurements. Experimental studies have shown that in order to achieve temperature fluctuations of no more than $\pm 0,07^{\circ} \mathrm{C}$ smoothing should be implemented over a time interval of $1 \mathrm{~s}$ for 100 measurements. Such a time interval was chosen based on the provision of 100 discrete power levels of the evaporator heating elements, which correspond to 100 half-periods of the mains voltage for $1 \mathrm{~s}$. A further increase in the value of this parameter is impractical, since a delay in the response of the PID controller to a change in the temperature of the heating elements begins to appear.

Experimental verification of the developed algorithm on a test bench has shown its efficiency and stability.

\section{REFERENCES}

[1] C.B. Kadua, C.Y. Patil. Design and Implementation of Stable PID Controller for Interacting Level Control System. Procedia Computer Science. Vol. 79, 2016, Pages 737-746.

[2] J. Farshad Merrikh-Bayat, Nafiseh Mirebrahimi, and Mohammad Reza Khalil. Discrete-time fractional-order PID controller: Definition, tuning, digital realization and some applications International Journal of Control, Automation, and Systems, 2015 Vol. 13(1), pp. 81-90.

[3] V. Chopra, S. K. Singla, and L. Dewan, "Comparative analysis of tuning a PID controller using intelligent methods," Acta Polytechnica Hungarica, vol. 11, no. 8, pp. 235-249, 2014.

[4] Semenets V. V., Kratts Dzh., Nevlyudov I. Sh., Palagin V. A. Tekhnologiya mezhsoedinenii elektronnoi apparatury. Ucheb. dlya vuzov. Khar'kov: «SMIT», 2005.

[5] Bambang Dwi Argo, Yusuf Hendrawan, Dimas Firmanda Al Riza, Anung Nugroho Jaya Laksono. Optimization of PID Controller Parameters on Flow Rate Control System Using Multiple Effect Evaporator Particle Swarm Optimization. International journal on advanced science engineering information technologies. Vol.5 (2015) No. 2. pp. 6-12. 